See discussions, stats, and author profiles for this publication at: https://www.researchgate.net/publication/295911956

\title{
Equine Amniotic Microvesicles and Their Anti-Inflammatory Potential in a Tenocyte Model In Vitro
}

Article in Stem cells and development · February 2016

DOI: 10.1089/scd.2015.0348

CITATIONS

14

13 authors, including:

Anna Lange-Consiglio

University of Milan

107 PUBLICATIONS 950 CITATIONS

SEE PROFILE

Giovanni Camussi

Università degli Studi di Torino

682 PUBLICATIONS 26,589 CITATIONS

SEE PROFILE

Some of the authors of this publication are also working on these related projects:

Project

extracellular vesicles View project

Project Immune Tuning Materials View project
READS

124

Claudia Perrini

24 PUBLICATIONS 85 CITATIONS

SEE PROFILE

Luisa Pascucci

Università degli Studi di Perugia

91 PUBLICATIONS 947 CITATIONS

SEE PROFILE 


\title{
Equine Amniotic Microvesicles and Their Anti-Inflammatory Potential in a Tenocyte Model In Vitro
}

\author{
Anna Lange-Consiglio,' Claudia Perrini, ${ }^{1}$ Riccardo Tasquier,, Maria Chiara Deregibus, \\ Giovanni Camussi, Luisa Pascucci, ${ }^{3}$ Maria Giovanna Marini, Bruna Corradetti, \\ Davide Bizzaro, Bruna De Vita, Pietro Romele, Ornella Parolini, and Fausto Cremonesi ${ }^{1,7}$
}

Administration of horse amniotic mesenchymal cells (AMCs) and their conditioned medium (AMC-CM) improves the in vivo recovery of spontaneous equine tendon lesions and inhibits in vitro proliferation of peripheral blood mononuclear cells (PBMC). This process may involve microvesicles (MVs) as an integral component of cell-to-cell communication during tissue regeneration. In this study, the presence and type of MVs secreted by AMCs were investigated and the response of equine tendon cells to MVs was studied using a dose-response curve at different concentrations and times. Moreover, the ability of MVs to counteract in vitro inflammation of tendon cells induced by lipopolysaccharide was studied through the expression of some proinflammatory genes such as metallopeptidase $(M P P) 1,9$, and 13 and tumor necrosis factor- $\alpha(T N F \alpha)$, and expression of transforming growth factor- $\beta(T G F-\beta)$. Lastly, the immunomodulatory potential of MVs was investigated. Results show that AMCs secrete MVs ranging in size from 100 to $200 \mathrm{~nm}$. An inverse relationship between concentration and time was found in their uptake by tendon cells: the maximal uptake occurred after $72 \mathrm{~h}$ at a concentration of $40 \times 10^{6} \mathrm{MVs} / \mathrm{mL}$. MVs induced a downregulation of $M M P 1, M M P 9, M M P 13$, and $T N F \alpha$ expression without affecting PBMC proliferation, contrary to CM and supernatant. Our data suggest that MVs contribute to in vivo healing of tendon lesions, alongside soluble factors in AMC-CM.

\section{Introduction}

$\mathrm{T}$ HERE ARE THREE regenerative mechanisms ascribed to mesenchymal stem cells (MSCs): (i) differentiation toward reparative or replacement cell types, (ii) enhancement of the nutrient supply, and (iii) improvement of the survival and function of endogenous cells through paracrine actions [1-3]. It is known that the inhospitable microenvironment of injured or degenerating tissues may result in the death or apoptosis of a large proportion of implanted MSCs in the short period immediately posttransplantation [4]. This raises the need to identify other mechanisms than differentiation of transplanted cells for the promotion of regeneration. This notion is supported by a recent study of Lange-Consiglio et al. [5] in which a conditioned medium (CM), derived from amniotic mesenchymal cells (AMCs), was injected into spontaneous injuries of equine tendons and ligaments and produced results consistent, and overlapping (in terms of time to complete healing), with the beneficial effects of transplanted AMCs as observed in the same animal model [6]. These results suggest that it may be possible to substitute cell treatment with the use of CM derived from the culture of these cells as the in vivo effects are mainly exerted by factors released from cells rather than through the direct cell-to-cell contact. This hypothesis was further supported by the evaluation of the immunosuppressive properties of AMC-CM, as peripheral blood mononuclear cell (PBMC) proliferation was inhibited by AMC-CM [5].

Secreted bioactive molecules may act as paracrine or endocrine mediators directly activating target cells and/or causing neighboring cells to secrete functionally active agents [7]. However, little is known about how the MSCs might release these secretions. Many of the secreted molecules cannot freely cross cell membranes, and a carrier is needed to facilitate the crossing [8]. It has recently been demonstrated that extracellular vesicles, or microvesicles

${ }^{1}$ Large Animal Hospital, Reproduction Unit, Università degli Studi di Milano, Lodi, Italy

${ }^{2}$ Department of Internal Medicine and Molecular Biotechnology Center, University of Torino, Torino, Italy.

${ }^{3}$ Department of Veterinary Medicine, University of Perugia, Perugia, Italy.

${ }_{5}^{4}$ Biochemistry, Biology and Genetics, Università Politecnica delle Marche, Ancona, Italy.

${ }^{5}$ Department of Animal Reproduction and Radiology, FMVZ, UNESP, Botucatu, San Paolo, Brazil.

${ }^{6}$ Centro di Ricerca E. Menni, Fondazione Poliambulanza, Istituto Ospedaliero, Brescia, Italy.

${ }^{7}$ Department of Veterinary Medical Science, Università degli Studi di Milano, Milano, Italy. 
(MVs), released from cells are an integral component of cell-to-cell communication in tissue regeneration $[9,10]$ and therefore may contribute to the paracrine action of MSCs. These vesicles can be categorized into exosomes and shedding vesicles. Exosomes arise from the endosomal membrane cell compartment and are released into the extracellular space after fusion of multivesicular bodies with the plasma membrane [11-13]. Shedding vesicles, also known as ectosomes or microparticles, originate from direct budding and 'blebbing' of the plasma membrane of many different cell types [11-13]. Exosomes tend to be homogeneous in size (30$120 \mathrm{~nm}$ ), while shedding vesicles are more heterogeneous (ranging from $100 \mathrm{~nm}$ to $1 \mu \mathrm{m}$ ). MVs express surface receptors and contain biologically active molecules such as proteins and lipids, as well as mRNA and microRNA [14].

Some in vivo studies have indicated that MVs could accelerate the recovery from acute kidney injury induced by glycerol in SCID mice [15], or significantly improve the recovery of blood flow in a rat hind limb ischemia model [16] suggesting that the therapeutic potential of MSC-derived MVs was similar to that of MSCs. Considering the in vivo results in spontaneous equine tendon lesions treated with $\mathrm{AMC}-\mathrm{CM}$ and the in vitro results on inhibition of PBMC proliferation [5], it appears reasonable to assume that MSCderived MVs act as mediators in the repair of tendon lesions. In this context, the aims of this study were to identify the presence and type of MVs secreted by AMCs and elucidate whether equine tendon cells can be the target of MVs in vitro. In addition, in an explorative study, we considered whether MVs are able to counteract an in vitro equine tendon cell inflammatory process induced by lipopolysaccharide (LPS) and their effect on inhibition of PBMC proliferation.

\section{Materials and Methods}

\section{Materials}

Tendon samples were collected from horses slaughtered in a national slaughterhouse under legal regulation. Chemicals were obtained from Sigma-Aldrich Chemical unless otherwise specified, and tissue culture plastic dishes were purchased from Euroclone.

\section{Study design}

Initially, amniotic cells were isolated and cultured to produce MVs that were characterized using Nanosight and transmission electron microscopy (TEM). Tendon cells were then isolated and specific tendon genes were identified by qualitative PCR. Isolated tendon cells were used as the target for different concentrations of MVs. Furthermore, the effect of MVs was analyzed by quantitative PCR expression of inflammatory genes on tendon cells treated by LPS and, last, the effect of MVs on inhibition of PBMC proliferation was also investigated.

\section{Tissues collection and cell isolation}

This study was approved by the Ethics Committee of the University of Milan and written owner consent was obtained. All procedures were conducted following standard veterinary practice and in accordance with 2010/63 EU directive on animal protection and Italian Law (D.L. No. 116/
1992). Allanto-amniotic membranes were obtained at term from normal pregnancies in three mares. Samples of allantoamnion were transported at $4{ }^{\circ} \mathrm{C}$ in calcium- and magnesiumfree phosphate-buffered saline (Euroclone) supplemented with $4 \mathrm{mg} / \mathrm{mL}$ amphotericin (Euroclone), $100 \mathrm{UI} / \mathrm{mL}$ penicillin$100 \mathrm{mg} / \mathrm{mL}$ streptomycin (Euroclone), and were processed within $12 \mathrm{~h}$ of collection. The amniotic membrane was mechanically separated from the allantois and the isolation of AMCs was performed as previously reported by LangeConsiglio et al. [17].

Superficial digital flexor tendon samples were aseptically collected from the mid-metacarpal region from three horses within $2 \mathrm{~h}$ of slaughtering (mean age: $7 \pm 3$ years). Tendon cells were isolated by stripping off the sheath and paratenon from tendon samples to obtain $2-3 \mathrm{~g}$ of trimmed tissue cut into small pieces with scalpel and scissors and then digested in HG-DMEM supplemented with $0.075 \%$ collagenase type I at $37.5^{\circ} \mathrm{C}$ overnight (about $16-20 \mathrm{~h}$ ). The digested suspension was filtered on an $80 \mu \mathrm{m}$ strainer, centrifuged at $400 \mathrm{~g}$ for $10 \mathrm{~min}$, and washed twice in PBS. Before seeding, cells were counted using a Burker chamber with the Trypan Blue dye exclusion assay.

\section{Cell culture and expansion}

Amniotic and tendon cell cultures were established in the HG-DMEM standard medium composed of $10 \%$ fetal calf serum (FCS), penicillin (100 UI/mL)-streptomycin $(100 \mu \mathrm{g} / \mathrm{mL}), 0.25 \mu \mathrm{g} / \mathrm{mL}$ amphotericin $\mathrm{B}$, and $2 \mathrm{mM}$ glutamine. The medium was supplemented with $10 \mathrm{ng} / \mathrm{mL}$ epidermal growth factor for AMC cultures. Cultures were established at a density of $1 \times 10^{5} \mathrm{cells} / \mathrm{cm}^{2}$ in T75 culture flasks. The flasks were incubated at $38.5^{\circ} \mathrm{C}$ with $5 \% \mathrm{CO}_{2}$ and $90 \%$ humidity. The medium was replaced after $72 \mathrm{~h}$ to remove nonadherent cells and then replaced twice weekly until cells reached approximately $80 \%$ confluence. Cells were then detached with $0.05 \%$ trypsin-EDTA (Euroclone), counted, and redistributed at a density of $1 \times 10^{4} \mathrm{cells} / \mathrm{cm}^{2}$ into new culture flasks to maintain and expand the culture for three passages $(\mathrm{P})$. Previous molecular biology analyses at P3 showed that these AMCs display a typical mesenchymal stromal phenotype, with the expression of markers such as CD29, CD44, CD106, CD105, and MHCI, but not of CD34 and MHCII, as reported by Lange-Consiglio et al. [17]. At P3, AMCs were used to obtain the CM or MVs and for the TEM analysis. At P3, tendon cells were used for the in vitro experiment with MVs and LPS, or cryopreserved in liquid nitrogen, using standard cryopreservation protocols, for the molecular biology study to confirm the characteristics of isolated cells.

\section{Preparation of $A M C-C M$}

AMCs at $\mathrm{P} 3$ were plated into 24-well plates at a density of $5 \times 10^{4}$ cells $/ \mathrm{mL} /$ well in DMEM standard medium. To generate AMC-CM, cells were cultured for 5 days at $37^{\circ} \mathrm{C}$ in a humidified atmosphere of $5 \% \mathrm{CO}_{2}$. Supernatants $(\mathrm{SN})$ from each plate were then collected, pooled, centrifuged at $700 \mathrm{~g}$, and stored at $+4^{\circ} \mathrm{C}$ until use. This procedure was performed for cells obtained from three different placentas. The final AMC-CM was obtained pooling the media obtained from different amniotic samples. 


\section{Isolation and measurements of MVs}

MVs were obtained from the culture media of AMCs derived from three different placentas, cultured for a week with HG-DMEM supplemented with 10\% MV-deprived FCS and overnight in HG-DMEM deprived of FCS, and supplemented with $0.5 \%$ of BSA (Sigma). The overnight culture media were centrifuged at 2,000 $\mathrm{g}$ for $20 \mathrm{~min}$ to remove debris, then at $100,000 \mathrm{~g}$ (Beckman Coulter Optima L-100K ultracentrifuge) for $1 \mathrm{~h}$ at $4^{\circ} \mathrm{C}$, washed in serum-free medium 199 containing N-2-hydroxyethylpiperazine-N-2-ethanesulfonic acid (HEPES) $25 \mathrm{mM}$ (Sigma), and submitted to a second ultracentrifugation under the same conditions. After ultracentrifugation, $\mathrm{SN}$ were stored at $+4^{\circ} \mathrm{C}$ until use for lymphocyte proliferation test, while the pellets were immediately resuspended in HG-DMEM, and a sample of the resuspended pellet was taken for measurements of MV size and concentration. A second fraction was labeled with fluorochrome PKH-26 and the remaining part of pellet was cryopreserved with $1 \%$ of dimethylsulfoxide at $-80^{\circ} \mathrm{C}$ and used for the in vitro test. Size and concentration of MVs were evaluated by the Nanosight LM10 instrument (Nanoparticle tracking analysis, NTA; Nano-Sight Ltd.), which permits discrimination of microparticles less than $1 \mu \mathrm{m}$ in diameter. The software (NTA 2.0 analytic software) allows the analysis of video images of particle movement under Brownian motion and the calculation of diffusion coefficient, sphere equivalent, and hydrodynamic radius of particles by using the Strokes-Einstein equation. This instrument was configured with a $405 \mathrm{~nm}$ laser and a high-sensitivity sCMOS camera (OrcaFlash2.8, Hamamatsu C11440; NanoSight Ltd.). Videos were collected and analysed using the NTA software with the minimal expected particle size, minimum track length, and blur setting, all set to automatic. Ambient temperature was recorded manually and did not exceed $25^{\circ} \mathrm{C}$. Five microliters of each sample was diluted in sterile physiological solution to a final volume of $1 \mathrm{~mL}$. Samples were analyzed within $15 \mathrm{~min}$ of the initial dilution with a delay of $10 \mathrm{~s}$ between sample introduction and the start of the measurement. For each sample, multiple videos of $30 \mathrm{~s}$ duration were recorded generating replicate histograms that were averaged.

\section{TEM of MVs}

For TEM analysis, AMCs were detached from the well by trypsin-EDTA and centrifuged at $600 \mathrm{~g}$ for $10 \mathrm{~min}$ to remove the culture medium. Cells were then fixed with $2.5 \%$ glutaraldehyde in $0.1 \mathrm{M}$ cacodylate buffer (CB) $\mathrm{pH} 7.3$, for $1 \mathrm{~h}$ at $4^{\circ} \mathrm{C}$. The pellet was subsequently washed twice in $\mathrm{CB}$, postfixed in $2 \%$ osmium tetroxide, dehydrated in a graded series of ethanol up to absolute, preinfiltrated, and embedded in Epon 812. Ultrathin sections $(90 \mathrm{~nm})$ were sectioned and mounted on 200-mesh copper grids, stained with uranyl acetate and lead citrate, and examined under a Philips EM 208 transmission electron microscope (TEM) equipped with a digital camera [University Centre for Electron Microscopy (CUME)_Perugia].

\section{MV labeling with $\mathrm{PKH}-26$}

To trace in vitro MVs by fluorescence microscopy, MVs from AMCs were labeled with the red fluorescence aliphatic chromophore intercalating into lipid bilayers PKH26 dye
(Sigma). Briefly: after ultracentrifugation, the MV pellet was diluted to $1 \mathrm{~mL}$ with the PKH-26 kit, and $2 \mu \mathrm{L}$ of fluorochrome were added to this suspension and incubated for $30 \mathrm{~min}$ at $38.5^{\circ} \mathrm{C}$. Thereafter, $7 \mathrm{~mL}$ of serum-free DMEM were added to the suspension that was ultracentrifuged again at $100,000 \mathrm{~g}$ for $1 \mathrm{~h}$ at $4^{\circ} \mathrm{C}$. The final pellet was immediately resuspended in HG-DMEM.

\section{Incorporation of MVs in tendon cells}

To study the capacity of MVs to be incorporated into tendon cells, a dose-response growth was performed in three replicates. Tendon cells were seeded at a density of $60 \times 10^{3}$ on culture slides ( $13 \mathrm{~mm}$; Nalgen Nunc International) in 24 wells and cocultured with 10-20-30-40-50×10 $\mathrm{MVs} / \mathrm{mL}$ labeled with PKH-26 dye, and preincubated or not with trypsin $(0.5 \mathrm{mM})$ for 24,48 , and $72 \mathrm{~h}$ at $38.5^{\circ} \mathrm{C}$. At the end of each experimental condition, cells were nuclear stained with $10 \mu \mathrm{g} / \mathrm{mL}$ of Hoechst 33343 for $15 \mathrm{~min}$ at $38^{\circ} \mathrm{C}$. The uptake of MVs was evaluated by an Olympus BX51 microscope equipped with a Scion Corporation 1394 video camera interfaced with a computer provided with software for image acquisition and analysis (Image-Pro Plus 5.1-Media Cybernetics; Immagini \& Computer). Excitation wavelength was positioned at $550 \mathrm{~nm}$, while emission wavelength was set at $567 \mathrm{~nm}$. Hoechst 33342 dye (Sigma) was excited at 353$365 \mathrm{~nm}$, while the emission wavelength was set at $460 \mathrm{~nm}$. To detect the intensity of fluorescence, a semiquantitative analysis was performed. Different images were acquired for each condition then, for each image, the area of interest (AOI; where the signal was present) was manually defined by the user. Inside the AOI, up to three different background signals were sampled. The background areas were positioned by the user only where the fluorescent signal was not specific. The maximum value collected from the background areas was then used to define the threshold. Only fluorescence with an intensity above the threshold was considered to indicate fluorescence due to labeled MVs. Finally, the program measured the signal intensity expressed in arbitrary unit (a.u.).

Confocal microscopy analysis to assess internalization of MVs was performed using a Leica SP2 laser scanning confocal microscope (Leica Microsystems Srl) equipped with a PL Fluotar 20x AN 0.5 Dry objective.

\section{In vitro effect of MVs on tendon cells treated with LPS}

Dose/response curve of LPS on tendon cells was studied showing that $100 \mathrm{ng} / \mathrm{mL}$ and $48 \mathrm{~h}$ were the dose and the time most effective in inducing cellular stress evaluated by apoptotic study (data not shown). Sixty thousand cells were incubated with and without LPS $(100 \mathrm{ng} / \mathrm{mL})$ in the presence or absence of $40 \times 10^{6} \mathrm{MVs} / \mathrm{mL}$ for 24 and $48 \mathrm{~h}$. Tendon cells at different times were used as control. At the end of each experimental condition, cells were detached with $0.05 \%$ trypsin-EDTA, centrifuged, and cryopreserved, for molecular biology studies, in liquid nitrogen using standard cryopreservation protocols.

\section{Molecular biology study}

After isolation from tendon tissue, cells were analyzed to detect the expression of specific tendon genes. Total RNA 
was extracted from tendon cells immediately after isolation (P0) using TRI Reagent Solution (Life Technologies). Samples were then treated with DNase to avoid DNA contamination. RNA concentration and purity were measured by Nanodrop Spectrophotometry (NanodropH ND1000). The cDNA was synthesized from total RNA (500 ng) using the PrimeScript RT reagent Kit (Takara Bio). The gene expression evaluation was performed using specific sequences; equine-specific oligonucleotide primers were designed using open source PerlPrimer software v. 1.1.17 based on available NCBI Equus caballus sequences or on mammal multialigned sequences. Primers were designed across an exon-exon junction to avoid genomic DNA amplification and their sequence conditions and the references used are shown in Table 1.

Conventional reverse transcription-PCR (RT-PCR) on tendon genes as tenascin $(T N)$, tenomodulin (TNDT), decorin $(D C N)$, and collagen type I (COL1A1) was performed in a $25 \mu \mathrm{L}$ final volume with RBC Taq DNA Polymerase (RBC Bioscience) under the following conditions: initial denaturation at $95^{\circ} \mathrm{C}$ for $2 \mathrm{~min}, 32$ cycles at $95^{\circ} \mathrm{C}$ for $30 \mathrm{~s}$ (denaturation), $55-60^{\circ} \mathrm{C}$ for $30 \mathrm{~s}$ (annealing), $72^{\circ} \mathrm{C}$ for $1 \mathrm{~min}$ (elongation), and final elongation at $72^{\circ} \mathrm{C}$ for $7 \mathrm{~min}$. For conventional PCR, primers were used at $300 \mathrm{nM}$ final concentrations.

After treatment of cells with LPS and MVs or CM, some specific genes involved in the inflammatory process were analyzed by RT-quantitative PCR (RT-qPCR) that was performed with SYBR green method in a MyiQ iCycler thermal cycler (Biorad). Matrix metallopeptidase 1 (MMP1), matrix metallopeptidase 9 (MMP9), matrix metallopeptidase 13 $(M M P 13)$, and tumor necrosis factor- $\alpha$ (TNF $\alpha)$ were proinflammatory genes selected for this study. Transforming growth factor- $\beta$ (TGF $\beta$ ) was evaluated as anti-inflammatory gene. Triplicate PCR reactions were carried out for each sample analyzed. The reactions were set on a strip in a final volume of $25 \mu \mathrm{L}$ by mixing, for each sample, $1 \mu \mathrm{L}$ of cDNA, $12.5 \mu \mathrm{L}$ of $2 \mathrm{X}$ concentrated SYBR Premix Ex Taq II (Takara Bio) containing SYBR Green as a fluorescent intercalating agent, $0.2 \mu \mathrm{m}$ forward primer, $0.2 \mu \mathrm{m}$ of reverse primer, and MQ water. PCR efficiencies were tested and found to be close to 1 . The thermal profile for all reactions was $30 \mathrm{~s}$ at $95^{\circ} \mathrm{C}$ and then 40 cycles of $5 \mathrm{~s}$ at $95^{\circ} \mathrm{C}$ and $30 \mathrm{~s}$ at $60^{\circ} \mathrm{C}$. Fluorescence monitoring occurred at the end of each cycle. Efficiency of amplification for each primer was monitored through the analysis of serial dilution. Additional dissociation curve analysis was performed and in all cases showed a single peak. The data thus obtained were analyzed using the iQ5 optical system software version 2.0 (BioRad). The expression of each gene was normalized to the reference gene glyceraldehyde-3-phosphate dehydrogenase (GAPDH) (internal control) to standardize the results by eliminating variation in cDNA quantity.

\section{PBMC isolation}

Horse PBMCs were obtained from heparinized whole blood samples, after informed consent was obtained from the owners, using density gradient centrifugation (Lymphoprep; AxisShield) at $500 \mathrm{~g}$ without brakes for $20 \mathrm{~min}$ at room temperature.

\section{PBMC proliferation test}

Proliferation was induced by stimulating PBMC $\left(2 \times 10^{5}\right.$ horse PBMC/well in a 96-well flat-bottomed plate) through the addition of phytohemagglutinin (PHA; Sigma) at a final concentration of $2 \mu \mathrm{g} / \mathrm{mL}$ in a final volume of $200 \mu \mathrm{L} / \mathrm{well}$ of RPMI complete medium. To study the effects of MVs on PBMC proliferation, MVs were used in different amounts: $100 \times 10^{6}, 50 \times 10^{6}$, and $5 \times 10^{6}$ in $100 \mu \mathrm{L}$ of DMEM supplemented with $0.1 \%$ penicillin/streptomycin and $10 \%$ FCS. The same concentrations of MVs were tested after sonication by Soniprep 150 instrument (MSE). PBMC proliferation was tested also with 170,120 , and $80 \mu \mathrm{L} /$ well of $\mathrm{CM}$ in its entirety and its SN obtained after centrifugation to separate the MVs.

All cultures were carried out in triplicate.

In all cases, PBMC proliferation was assessed after 3 days of culture by adding $0.67 \mu \mathrm{Ci}$ per well (96-well tissue culture plates) of $[3 \mathrm{H}]$-thymidine (INC Biomedicals) for 16 $18 \mathrm{~h}$. Cells were then harvested with a Filtermate Harvester (PerkinElmer), and thymidine incorporation was measured using a microplate scintillation and luminescence counter (Top Count NXT; PerkinElmer).

Table 1. Primer Sequences and Characteristics

\begin{tabular}{|c|c|c|c|}
\hline Markers & Forward & Reverse & $b p$ \\
\hline Decorin $(D E C)$ & CCAATGTTCTGATTTGGGTCTG & GTTGTTGACAAGAATCAACGC & 152 \\
\hline Tenomodulin $(T N M D)$ & CCATGCTGGATGAGAGAGGT & GTTGCAAGGCATGATGACAC & 152 \\
\hline Tenascin-C (TEN) & CAAGTTCACAACAGACCTC & AGGTCGTGTCTCCATTCAG & 184 \\
\hline Collagen type I (COL1A1) & CTACGATGGCTGCACGAGTC & GACAGGGCCAATGTCGATGC & 151 \\
\hline $\begin{array}{l}\text { Matrix metallopeptidase } 1 \\
\quad(M M P 1)\end{array}$ & ACTGCCAAATGGACTTCAAGCTGC & TCTTCACAGTGCTAGGAAAGCCG & 158 \\
\hline $\begin{array}{l}\text { Matrix metallopeptidase } 9 \\
\text { (MMP9) }\end{array}$ & CGACGAAGAGTTGTGGTCTCTGG & GCGGTCGGTGTCATAGTAGGC & 184 \\
\hline $\begin{array}{l}\text { Matrix metallopeptidase } 13 \\
\quad(M M P 13)\end{array}$ & СTCTGGTCTGCTGGCTCACGC & CCAAACTCGTGTGCAGCGAC & 132 \\
\hline $\begin{array}{l}\text { Tumor necrosis factor- } \alpha \\
\qquad(T N F \alpha)\end{array}$ & GCCTCAGCCTCTTCTCСTTC & GGCTTGTCACTTGGGGTTC & 172 \\
\hline $\begin{array}{l}\text { Transforming growth factor- } \beta \\
\quad(T G F \beta)\end{array}$ & GGAATGGCTGTCCTTTGATG & CGGAGTGTGTTATCTTTGCTGTC & 120 \\
\hline $\begin{array}{l}\text { glyceraldehyde-3-phosphate } \\
\text { dehydrogenase (GAPDH) }\end{array}$ & TAACGTGTCAGTCGTGGATC & TTGTCATACCAGGAAATGAGC & 234 \\
\hline
\end{tabular}




\section{Statistical analysis}

For quantitative PCR data, nonparametric tests were used. The Mann-Whitney U-test was employed to compare two groups (treated vs. untreated). Results were considered statistically significant if the value of $P$ was $<0.05$.

For PBMC proliferation test, paired $t$-test, baseline corrected unpaired $t$-test, and ANOVA plus Tukey's test were used with GraphPad Prism software, version 6. Results were considered statistically significant if the value of $P$ was $<0.05$.

\section{Results}

\section{Tissue collection and cell isolation}

Cells were selected purely on their ability to adhere to plastic. For AMCs, initial viability was $>90 \%$, whereas for tendon cells it was $>80 \%$. Amniotic cells (Fig. 1A) and tendon cells (Fig. 1B) displayed typical fibroblast-like morphology. AMCs observed at the early stages of culture were organized as three-dimensional clusters (Fig. 1C).

The molecular biology study on tendon cells confirmed that these cells were tendon cells because of the expression of TN, TNMD, DCN, and COLIAI.

\section{Isolation and measurements of MVs}

In all studied samples, the viability of AMCs at the time of MV collection was $99 \%$ as detected by trypan blue exclusion.
By Nanosight, the size of MVs ranged from 50 to $670 \mathrm{~nm}$, with a mean size of $258 \pm 55 \mathrm{~nm}$ for three samples. The number of MVs ranged from 800 to 4,700 particles/cell, with a mean value of $2,550 \pm 71$ particles/cell (corresponding to $540 \times 10^{6}$ particles $/ \mathrm{mL}$ of medium).

\section{TEM of MVs}

TEM revealed the presence of variably sized, extracellular membranous vesicles budding from or lying near the source cell and characterized by an electron-lucent or moderately electron-dense content (Fig. 2A, B). The size of MVs varied from about 100 to $1,000 \mathrm{~nm}$, with a predominance of vesicles between 100 and $200 \mathrm{~nm}$. The vesicles were roughly spherical.

Although active budding was not frequently observed, it is believed that, because of size and morphological characteristics, the vesicles observed were mainly shedding vesicles (microvesicles), rather than exosomes. Multivesicular bodies in the early stages of maturation were occasionally detected (Fig. 2C). This suggests that the production of exosomes by these cells is less relevant compared with shedding vesicles.

\section{Incorporation of MVs in tendon cells}

As seen by fluorescence microscopy, in all studied samples, no fluorescence signal was detectable up to the sixth hour of coincubation of MVs, and tendon cells and only
FIG. 1. Morphology of amniotic (A) and tendon cells (B). AMCs observed at the early stages of culture organized as three-dimensional clusters (C). Results of molecular biology study on tendon cells (D). AMC, amniotic mesenchymal cell.

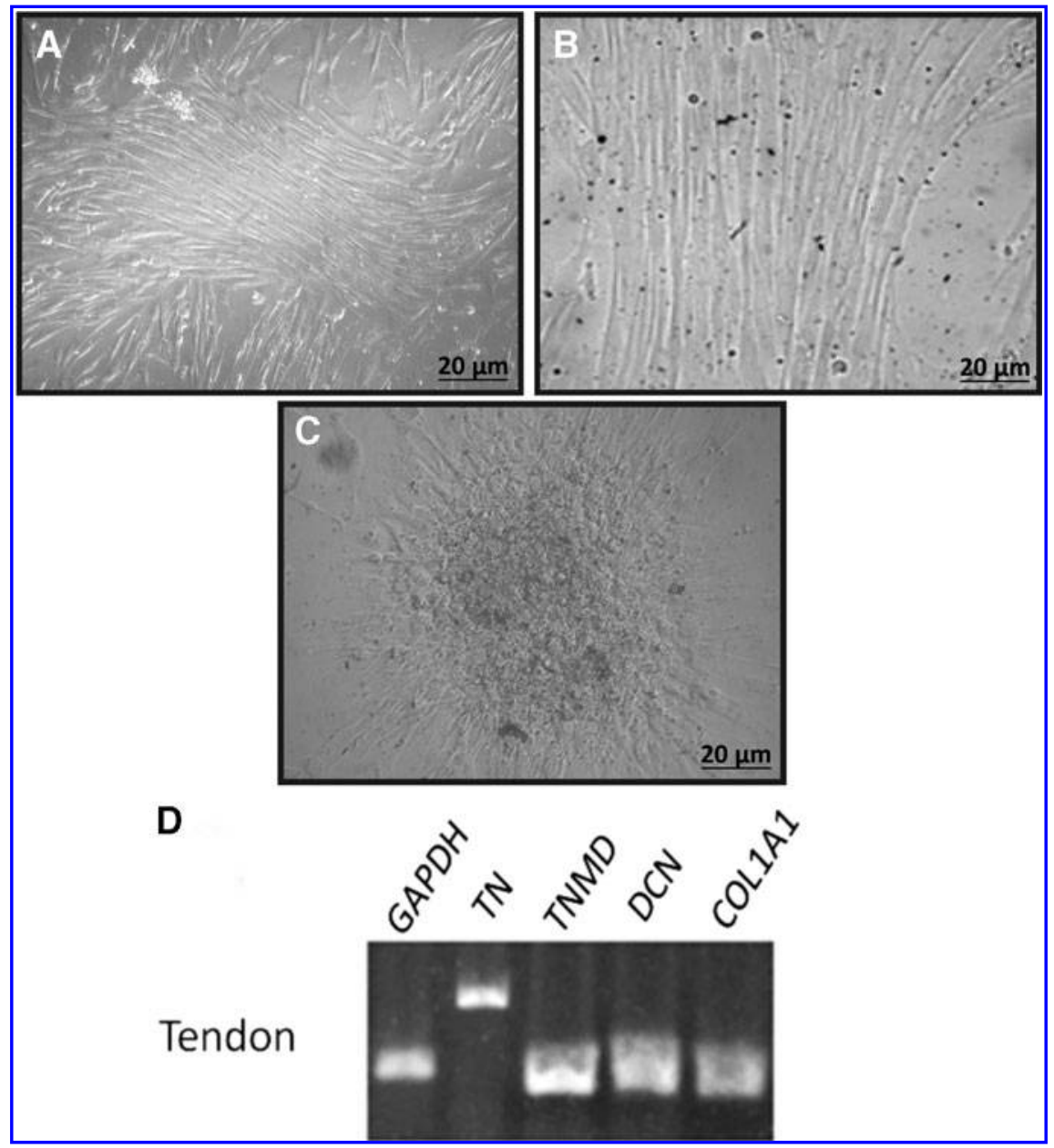




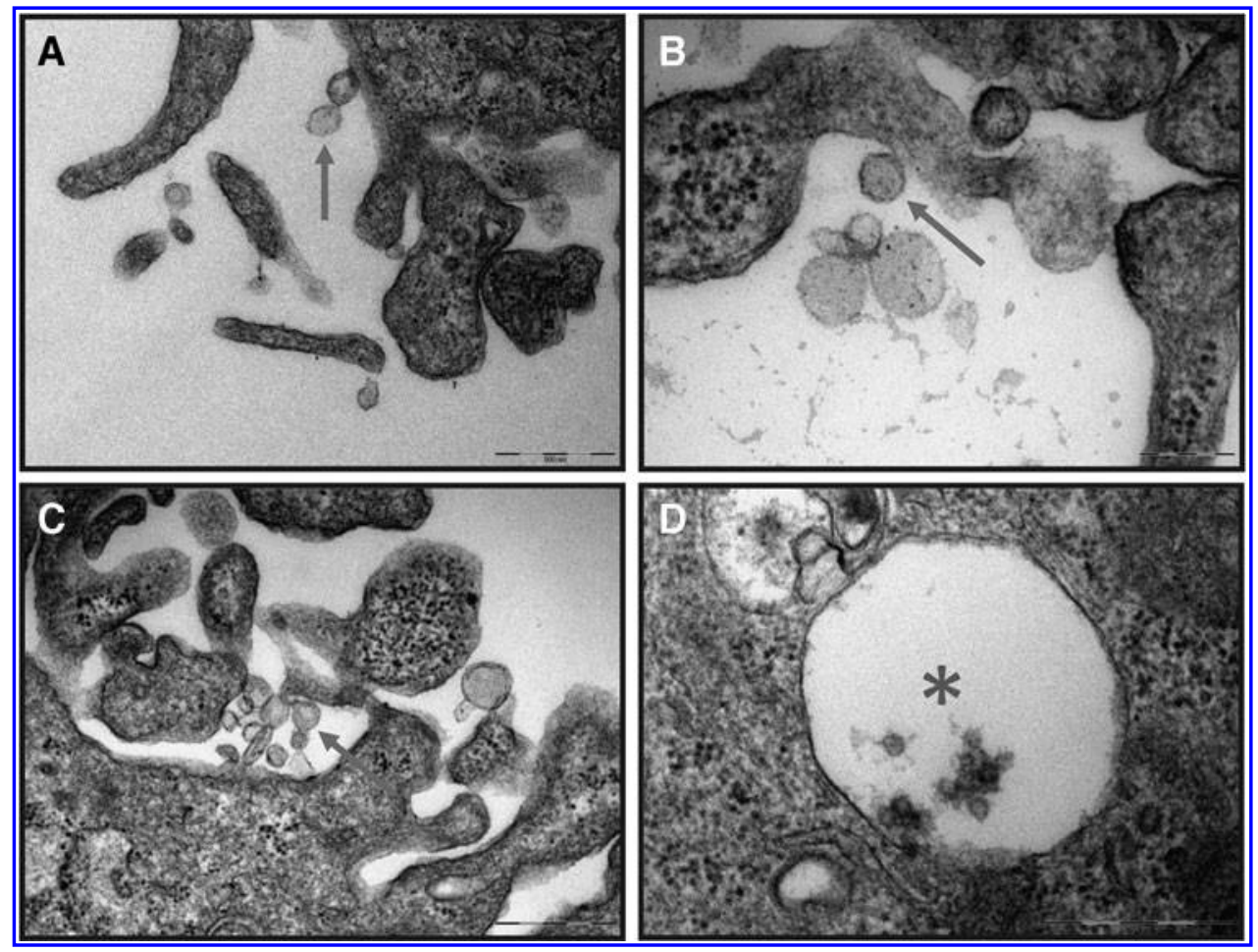

FIG. 2. Electron microscopy analysis of MVs. (AC) Arrows show the release of MVs from the surface of an AMC. Asterisk shows a multivesicular body in the early stage of maturation (D). Scale bar: $500 \mathrm{~nm}$ for $(\mathbf{A}, \mathbf{C}$, and D), $200 \mathrm{~nm}$ for (B). MV, microvesicle.

nuclei stained with Hoechst 33342 were visible (Fig. 3A). Neither was any signal detected after treatment of MVs with trypsin. When MVs were incorporated into cells, a fine granular fluorescent pattern was detectable within the cytoplasm, indicating the incorporation of labeled MVs. Under a fluorescent microscope, the tendon cell nuclei (blue), the MVs (red), and the merged image, show the incorporation of MVs into the target cells (Fig. 3B-D). The internalization and accumulation of MVs peaked between 24 (Fig. 3E) and 72 (Fig. 3F) h.

As seen by confocal microscopy, after $24 \mathrm{~h}$ of incubation with MVs, tendon cells showed a fine granular fluorescent pattern within their cytoplasm, indicating incorporation of MVs (Fig. 4).

At higher concentrations, uptake rate was faster: $50 \times 10^{6}$ MVs were incorporated in $24 \mathrm{~h}, 40 \times 10^{6} \mathrm{MVs}$ in $48 \mathrm{~h}$, and $30 \times 10^{6}$ MVs in $72 \mathrm{~h}$ (Fig. 5). Moreover, the uptake of MVs drastically increased at $72 \mathrm{~h}$ at a concentration of $40 \times 10^{6}$ MVs and decreased at the concentration of $50 \times 10^{6} \mathrm{MVs}$ (Fig. 6).

\section{In vitro effect of MVs on tendon cells treated with LPS}

The expression of some proinflammatory genes was evaluated by RT-qPCR and nonstimulated tendon cells were used as a control. Data were obtained from three samples. A moderate, but significantly $(P<0.05)$ increased gene expression of $M M P 1(1.6 \pm 0.14)$ and $M M P 9$ (4.4 \pm 0.14$)$ was observed compared to tendon cells $48 \mathrm{~h}$ after exposure to LPS (Fig. 6). A significantly higher expression of $M M P 13$ (16.7士 $0.12)$ and $\mathrm{TNF} \alpha(8.47 \pm 0.42)$ were noticed $48 \mathrm{~h}$ after LPS exposure compared to baseline levels (Fig. 7). The presence of MVs had a significant effect on the gene expression of metallopeptidases when compared to expression levels of control. In particular, a striking reduction in the expression levels for $M M P 1(0.77 \pm 0.2), M M P 9$ (2.4 \pm 0.18$)$, $M M P 13(7.22 \pm 0.18)$, and $T N F \alpha(3.42 \pm 0.21)$ was found at $48 \mathrm{~h}$ after addition of MVs. At $24 \mathrm{~h}$, the combination of LPS and MVs increased the expression of MMP9. Tendon cells constitutively express $T G F \beta$ that decreased after LPS treatment, but it is restored from MVs.

\section{PBMC proliferation test}

Through in vitro studies, we demonstrated that MVs did not inhibit PBMC proliferation after activation with PHA even after sonication of them (Fig. 8). The only inhibitor effect was evident with $\mathrm{CM}$ in its entirety and its $\mathrm{SN}$ obtained after centrifugation to isolate MVs (Fig. 8), without a statistical difference between them. The inhibitory effect was dose dependent either with the $\mathrm{CM}$ or its $\mathrm{SN}$ with significant effect at 170 and $120 \mu \mathrm{L}$, but not with $80 \mu \mathrm{L}$.

\section{Discussion}

AMCs are the focus of great interest in veterinary regenerative medicine for their in vitro multilineage differentiation potential, their great in vitro expansion, and for their potential therapeutic applications in vivo in spontaneous equine tendon lesions [5]. Their paracrine effects have been demonstrated in in vitro and in vivo [6] studies, suggesting that soluble factors are implicated in the AMC effects and cell-cell contact is not necessary for their action. Cell-derived MVs were described as a new mechanism for cell-to-cell communication [18], indeed, MVs are released by a variety of cell types, [18,19] including stem cells and progenitor cells $[9,20]$. In this study, we investigated whether equine AMCs produce MVs and if tendon cells could be targeted by them. Our results show that AMCs secret MVs 


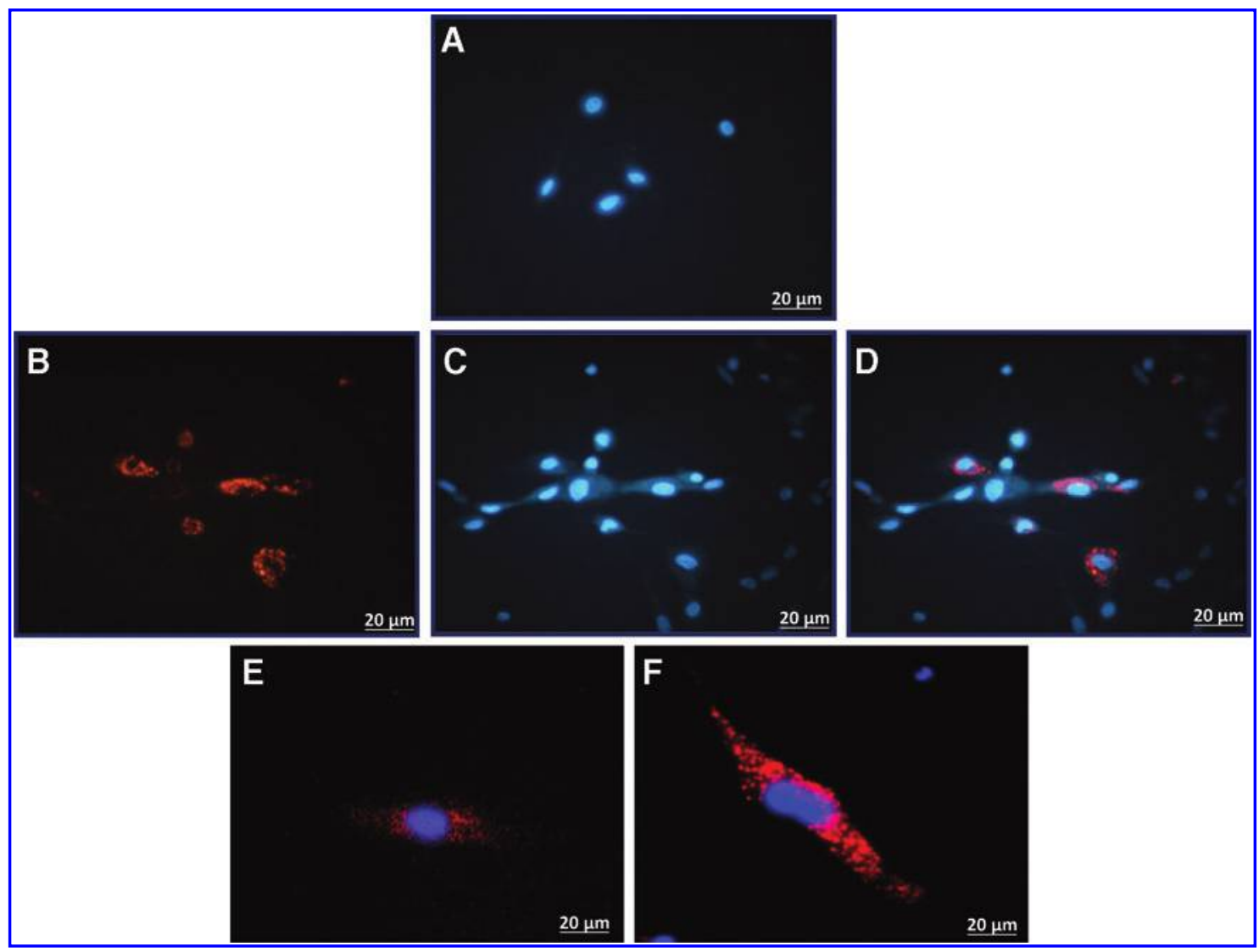

FIG. 3. Representative micrographs of internalization by tendon cells of MVs labeled with PKH-26. Under a fluorescent microscope, the tendon cell nuclei (blue), the MVs (red), and the merged image, which show incorporation of MVs into the target cells. (A) No incorporation of MVs preincubated with trypsin. MVs (B), tendon cell nuclei (C) and merged image (D) show the incorporation of MVs into the target cells. (E) Internalization in tendon cell at $24 \mathrm{~h}$ and (F) $72 \mathrm{~h}$. Color images available online at www.liebertpub.com/scd

FIG. 4. Representative $\mathrm{z}$ stack micrographs showing the internalization of MVs as detected by confocal microscopy in tendon cells cocultured with MVs for $24 \mathrm{~h}$. (A) The images were taken at different plans scanned every $0.5 \mu \mathrm{m}$ from top to bottom of the nucleus. (B) Orthogonal projection of the same group of cells. Color images available online at www.liebertpub .com/scd

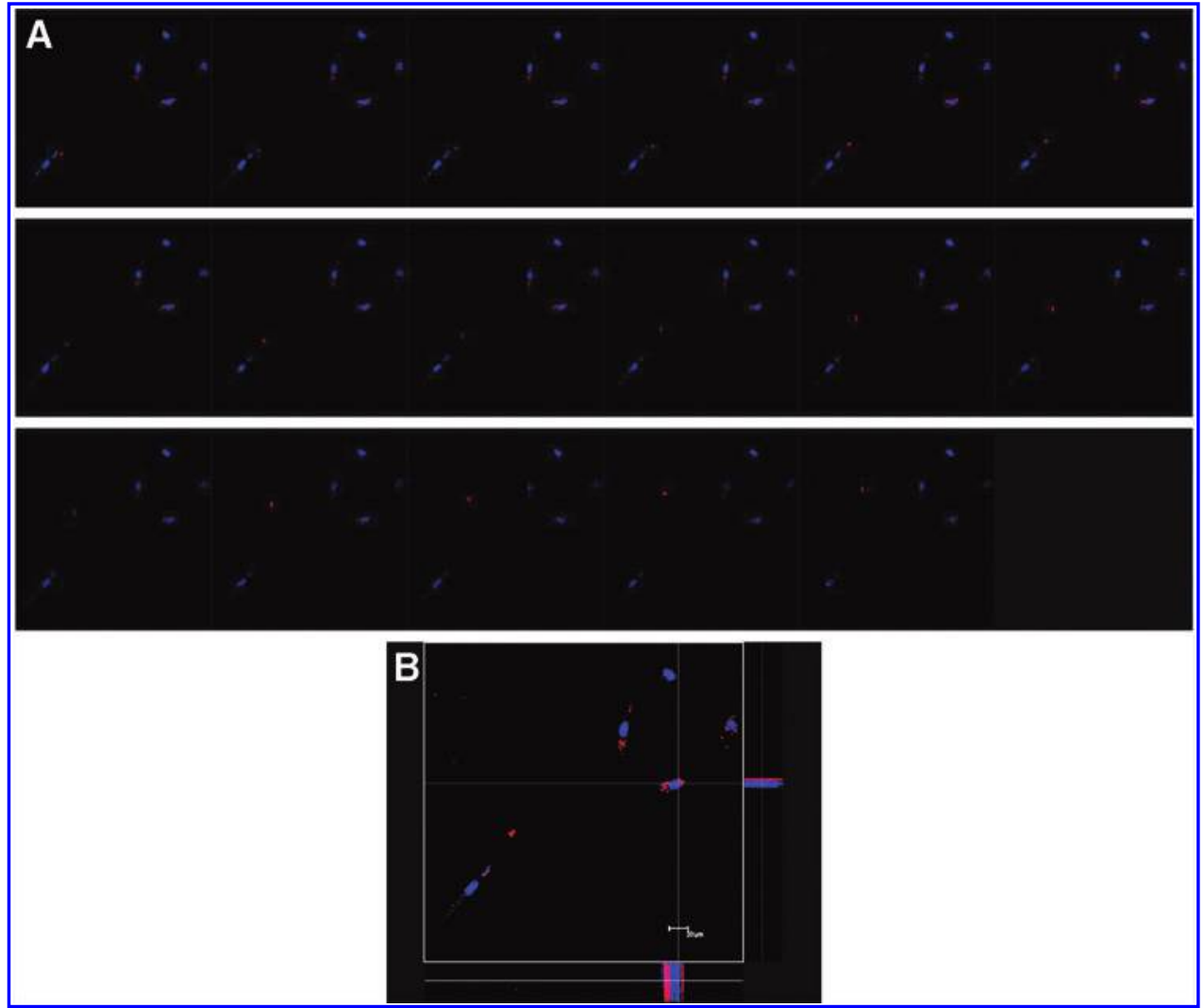




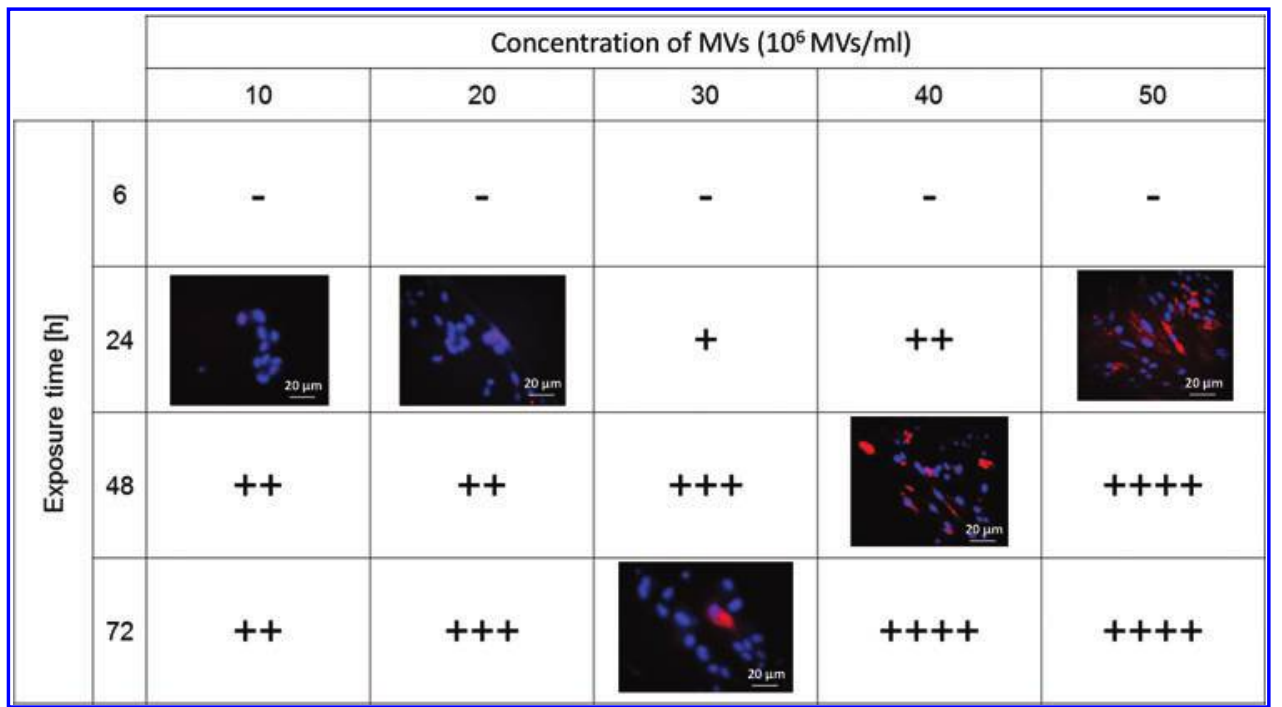

FIG. 5. Micrographs of dose/exposition time for MV incorporation. No fluorescence signal was detectable up to the sixth hour of coincubation of MVs and tendon cells. At higher concentrations, the uptake rate was higher: $50 \times 10^{6} \mathrm{MVs}$ were incorporated in $24 \mathrm{~h}, 40 \times 10^{6}$ $\mathrm{MVs}$ in $48 \mathrm{~h}$, and $30 \times 10^{6}$ MVs in $72 \mathrm{~h}$. Color images available online at www .liebertpub.com/scd

(with a mean size of $258 \mathrm{~nm}$ ) as detected by a Nanosight instrument. The TEM analysis confirmed this size, underlining that the vesicles observed are mainly shedding vesicles or MVs. Indeed, the production of exosomes by these cells was more rarely detected. An interesting finding is the number of MVs that these cells are capable of secreting. In our experimental conditions, each amniotic cell, plated at a density of $1 \times 10^{4}$ cells $/ \mathrm{cm}^{2}$, is able to secrete approximately $2,550 \mathrm{MVs}$, corresponding to about $540 \times 10^{6}$ particles $/ \mathrm{mL}$ of SN. Moreover, we found that MVs are easily internalized by tendon cells. Fluorescent microscopy analysis suggests that the uptake of MVs by tendon cells shows an inverse relationship between concentration and time. Indeed, the highest concentrations are internalized in a shorter time and, vice versa. The behavior of the cells stimulated with MVs for $72 \mathrm{~h}$ is surprising. More MVs (determined by semiquantitative analysis) are incorporated at $72 \mathrm{~h}$ when compared to other studied times, but after a peak of internalization with $40 \times 10^{6} \mathrm{MVs} / \mathrm{mL}$, there is an abrupt decrease of fluorescence intensity detected at $50 \times 10^{6} \mathrm{MVs} /$ $\mathrm{mL}$. Obviously, the target cell is able to incorporate MVs, but it must be able to use their contents too. We hypothesize that after $72 \mathrm{~h}$ of exposure at $40 \times 10^{6} / \mathrm{mL}$, the cells are saturated and phagocytosis of MVs, for the release of their contents into the cell cytoplasm, begins. This phagocytosis probably results in the destruction of the MV membranes and, consequently, in the loss of fluorescence signal. A mechanism for internalization as a result of the direct fusion or endocytic uptake by target cells was demonstrated by Cocucci et al. [21]. Once internalized, the MVs can fuse their membrane with that of endosomes, making a horizontal transfer of their contents into the cytoplasm of the recipient cells. Alternatively, MVs can remain segregated inside the endosomes and be phagocytized by lysosomes or eliminated from the cells after fusion with the plasma membrane through a mechanism of transcytosis [21]. Our data show that horizontal transfer of the contents of MVs within tendon cells could be one of the mechanisms of action of MVs, although other methods of interaction may occur simultaneously. Indeed, the lack of MV internalization by tenocytes after treatment with trypsin is interesting. Presumably, the interaction between membrane receptors of

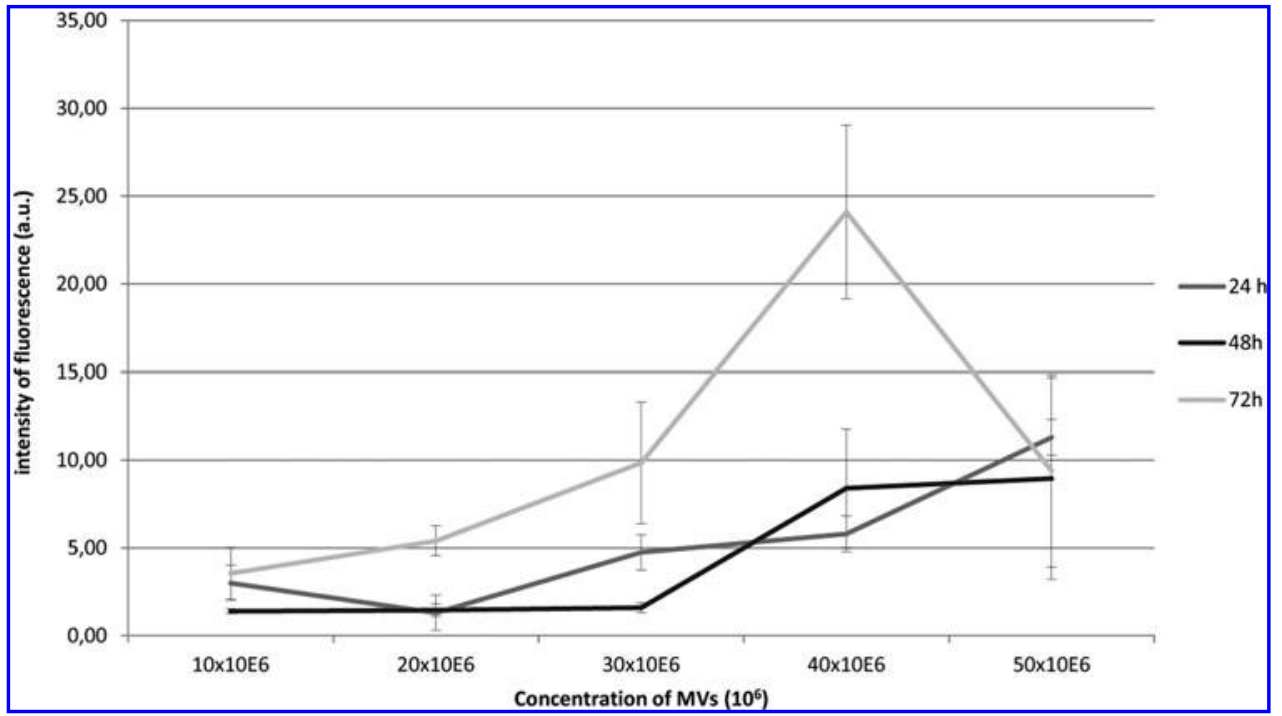

FIG. 6. Graph of dose/exposition time for MV incorporation. The uptake of MVs drastically increased at $72 \mathrm{~h}$ at $40 \times 10^{6}$ MVs and decreased at $50 \times 10^{6}$ MVs. Data represent the mean and SD of at least three independent experiments. In the curve of $72 \mathrm{~h}$, values labeled with different letters are statistically different $(P<0.05)$. 


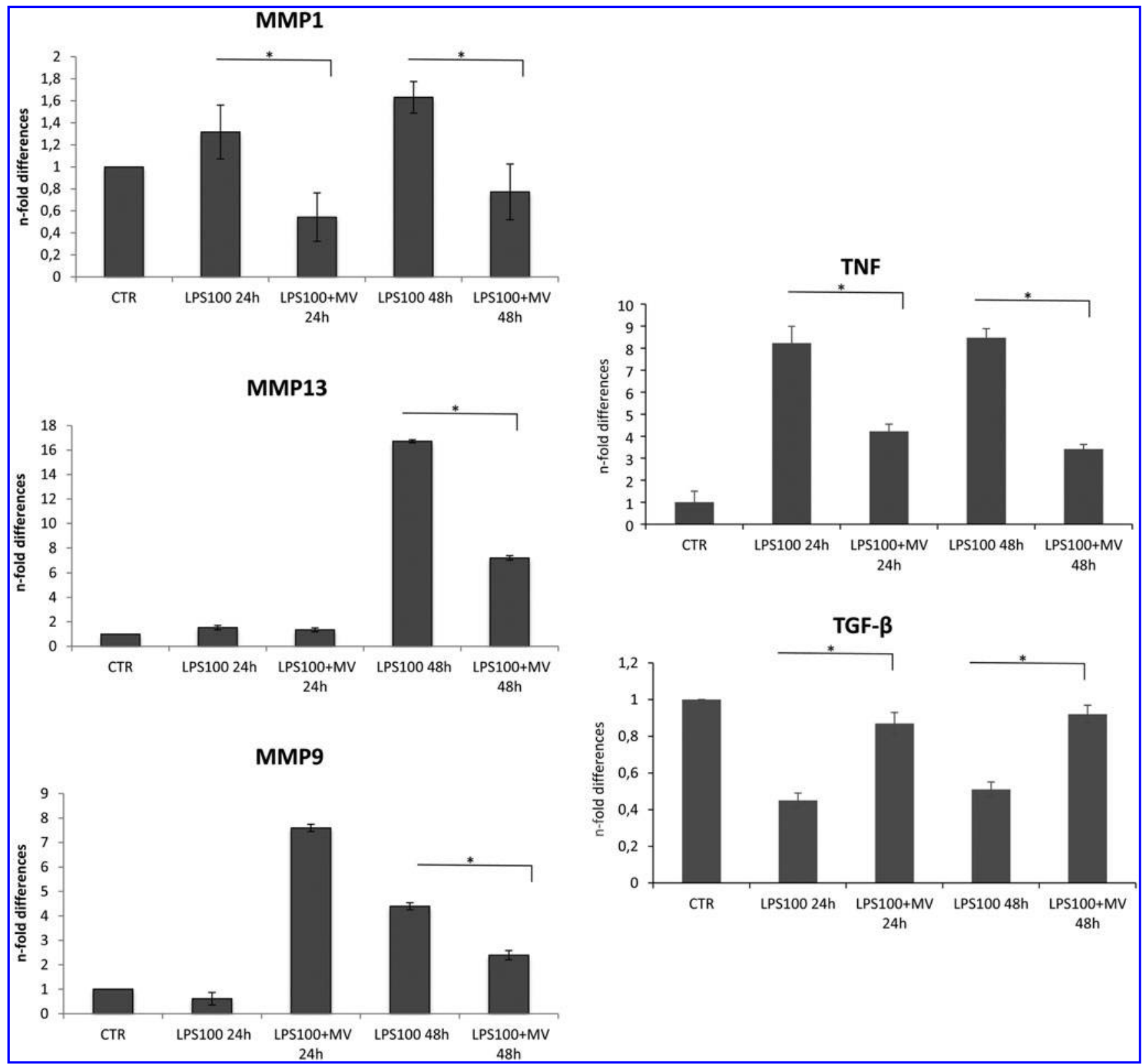

FIG. 7. Quantitative RT-PCR analysis for the expression of $M M P 1, M M P 9, M M P 13, T N F \alpha$, and $T G F \beta$ genes. Cells were cultured in presence of $100 \mathrm{ng} / \mathrm{mL}$ LPS with or without MVs at 24 and $48 \mathrm{~h}$. Expression levels have been normalized to the reference gene $(G A P D H)$. Data are represented as fold change compared with the expression observed in tendon cells (control). Values are mean $\pm \mathrm{SD}(n=3)$. Asterisks depict significant $(* P<0.05)$ differences. LPS, lipopolysaccharide; RTPCR, reverse transcription-PCR.

the MVs and target cell surface receptors is required for the process of internalization. The removal of surface molecules by trypsin treatment inhibits their incorporation, confirming the importance of surface molecules in the internalization of MVs. Bruno et al. [15] found that MSC-derived MVs expressed several adhesion molecules of MSCs such as CD44, CD29 ( $\alpha 1$-integrin), $\alpha 4$ - and $\alpha 5$ integrins, and CD73, but not $\alpha 6$ integrin. Some of these molecules, namely CD44 and CD29, were found to be instrumental in MV internalization into tubular endothelial cells, as treatment with anti-CD44 and anti-CD29 blocking antibodies prevented MV incorporation. In our study, the simple treatment with trypsin and the subsequent failure of incorporation of MVs into tendon cells confirm a process of interaction between the receptor and the target cells before internalization of MVs.

Having identified that the tendon cells represent target cells for MVs secreted by equine AMCs, a further aim of this study was to understand whether or not these MVs might be involved in the regeneration of tendon injuries previously treated in vivo with AMC-CM [6]. Obviously, due to the difficulty of studying the repair systems of spontaneous tendon pathology in vivo, we recapitulated in vitro the inflammatory process by stimulating cells with LPS. The inflammatory process is essential because the activation of the inflammatory cascade is an important stimulus for tendon healing, although persistent inflammation is believed to be the 


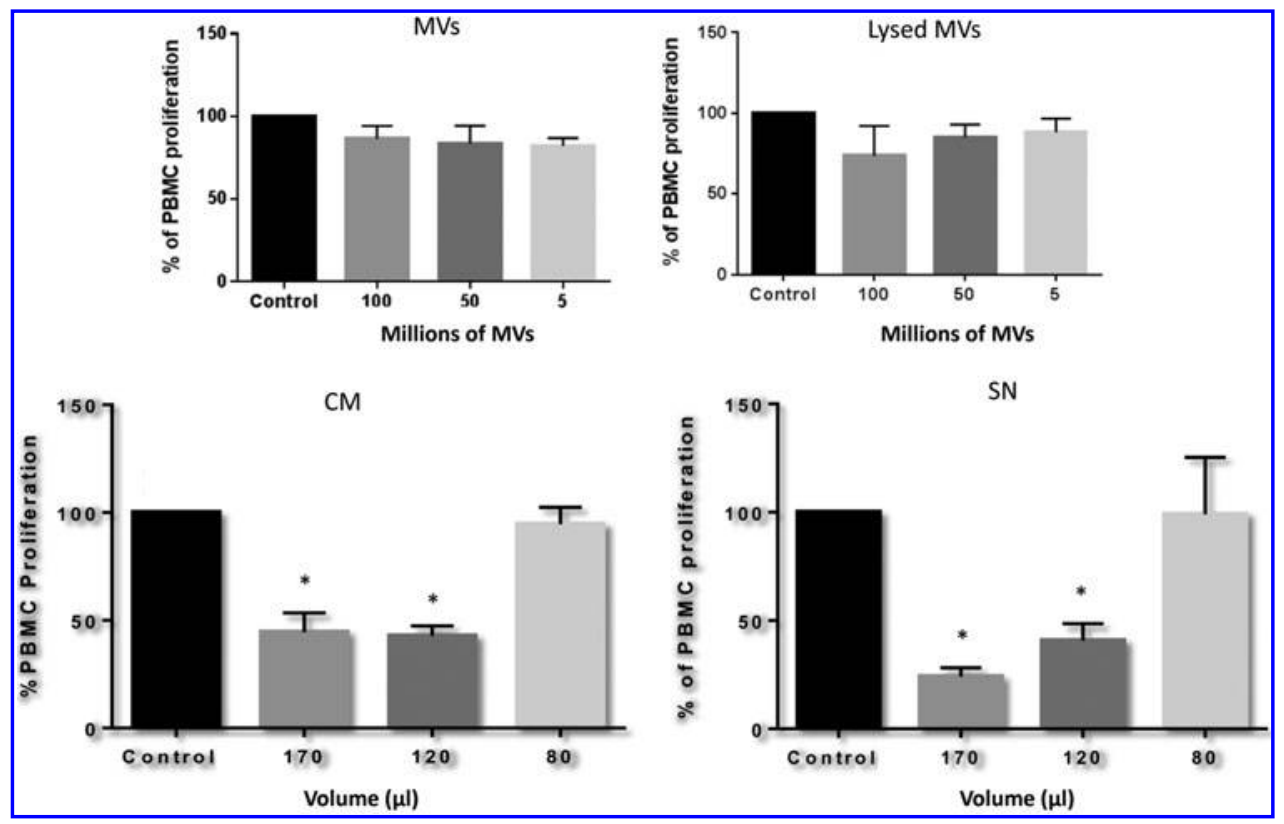

FIG. 8. Lymphocyte proliferation test. Effects of different amounts (100-50$5 \times 10^{6}$ ) of MVs per $\mathrm{mL}$ and different amount of CM and $\mathrm{SN}$ on the proliferation of PHA-stimulated lymphocytes $(\mathrm{PBMC}+\mathrm{PHA})$. Data represent the mean and SD of at least three independent experiments. $* P<0.05$ versus Control (PBMC + PHA). CM, conditioned medium; PBMC, peripheral blood mononuclear cell; SN, supernatant.

cause of fibrosis that is counterproductive to achieve a successful healing [22]. In physiological conditions, inflammation becomes self-regulating within the first $24-48 \mathrm{~h}$ following an insult [23]. For this reason, the in vitro experiment was set at $48 \mathrm{~h}$. In this explorative study, we analyzed TNF- $\alpha$, which it is a proinflammatory cytokine that mediates inflammation [24] and genes involved in tendon extracellular matrix degradation. In addition, expression of TGF $\beta$ was assessed. Following $48 \mathrm{~h}$ treatment with LPS at $100 \mathrm{ng} / \mathrm{mL}, M M P 1$ and $M M P 9$ expression increased moderately, while $M M P 13$ and $T N F \alpha$ expression increased more than control. The MMPs are a family of structurally related zinc-/calcium-dependent proteinases that play a central role in the extracellular matrix degradation during both normal and pathological tissue remodeling processes [25,26]. Nomura et al. [27] demonstrated that in equine superficial digital flexor tendinitis, $M M P 1$ was not detected at mRNA level, while $M M P 13$ was upregulated in the tendinitis compared to normal tendon, suggesting that MMP13 plays an important role in tendon injuries in the racehorse. Although the origin of these MMP13-expressing cells in the tendinitis is still not clear, we hypothesize that this enzyme could be involved in the process of superficial digital flexor tendinitis development. Expression of $M M P 9$ has been reported to increase in horses with insulin-induced laminitis compared with control horses [28], so it is plausible that in our static in vitro system, with LPS treatment, the $M M P 9$ is moderately expressed. These data confirm our results regarding the moderate increase of $M M P 1$ and $M M P 9$ compared to MMP13 in the LPS treatment.

Since treatment with LPS induced an inflammatory response, an explorative study to understand the mechanism of action by MVs was performed. The single concentration of $40 \times 10^{6} \mathrm{MVs} / \mathrm{mL}$ was used because, during the study of internalization, neither were tendon cells saturated with MVs at this concentration at $48 \mathrm{~h}$ of culture nor did MV degradation start. In this experiment, MVs downregulated the expression of $M M P 1, M M P 9, M M P 13$, and $T N F \alpha$ genes at $48 \mathrm{~h}$ of LPS treatment and restored the expression of $T G F \beta$ that is constitutively expressed by tendon cells. At $24 \mathrm{~h}$, the combination of LPS and MVs increased unexpectedly the expression of $M M P 9$. This behavior was consistent in all three experiment replicates. From our data not shown, MVs alone do not induce an upregulation of the genes studied at different time, but apparently, the combination of LPS and $\mathrm{MVs}$ induced an inflammatory process. In tendon lesion, the presence of MMP9 is remarkable, but its presence is probably related to invading cells and their factors [29]. In our in vitro context at $24 \mathrm{~h}$, MVs could have introduced factors (such as miRNA) that, acting as an inflammatory process, temporarily enhanced the expression of $M M P 9$ that is reinstated at $48 \mathrm{~h}$ by MVs themselves.

The last study was the PBMC proliferation inhibition by MVs to confirm that the inhibition obtained by AMC-CM [5] was due to the paracrine factors that communicate with immune cells. However, the finding that inhibition of PBMC proliferation was induced only by whole CM or by its $\mathrm{SN}$ and not by MVs suggests that this competence is imputable to factors (growth factors) not contained in MVs. This hypothesis was further supported by our findings that PBMC proliferation was not inhibited by the sonicated or lysed MVs. A similar effect was recently reported by Del Fattore et al. [30] with bone marrow-derived extravesicle (EV) that induced T-cell apoptosis without significantly suppressing $\mathrm{T}$-cell proliferation, even if $\mathrm{EV}$ treatment increased the Treg/Teff ratio and the immunosuppressive cytokine IL-10 concentration in the culture medium. The divergent effects of AMC-CM and MVs on PBMC stimulated with PHA are at present unexplained. Even though it is generally accepted that MSCs from amniotic membrane or other sources act in a paracrine manner (for review [31-33]), from our study, it is possible to hypothesize that the effect of these mechanisms is mainly due to soluble factors and not the cargo of MVs. Although many studies failed to detect those cytokines and growth factors that are present in low concentrations [34], TGF- $\beta 1$, hepatocyte growth factor, prostaglandin $\mathrm{E} 2$, interleukin-10, haem oxygenase-1, interleukin-6, and human leukocyte antigen-G5 are all known to be constitutively produced by MSCs [35-37]. Recently, Rossi et al. [38] suggested that prostaglandins as one of the key effector 
molecules of the antiproliferative activity of human amniotic membrane-derived cells. However, the divergent effects of AMC-CM and MVs on PBMC stimulated with PHA are at present unexplained and, as demonstrated by Del Fattore et al. [30], appear to be different from those exhibited by their cells of origin. In this context, the immunosuppressive effects of MVs cannot be ruled out since more studies are required regarding $\mathrm{MVs}$ and lysed MV influence on the different lymphocytic subpopulations.

\section{Conclusion}

Our preliminary results demonstrate that AMCs produce MVs that are able to target tendon cells. Moreover, these $\mathrm{MVs}$, in our explorative experimental conditions, exerted anti-inflammatory effects although they were not able to suppress immune cell activity in vitro. This let us assume that in therapeutic in vivo administration of $\mathrm{CM}$, for the treatment of spontaneous equine tendon injuries [6], both MVs' cargo and soluble factors contributed to the regenerative effect. Additional works will be needed to better understand both, the efficacy and the mechanisms of action of this novel potential tool, which will change the perspective of the therapeutic use of MSCs in tendon lesions, or in inflammatory process-based diseases, considering the MVs as a cell-free therapy.

\section{Acknowledgments}

This study was supported by grants from Università degli Studi di Milano, Milano, Italy; Università Politecnica delle Marche, Ancona, Italy; and by Centro di Ricerca E. Menni, Fondazione Poliambulanza, Istituto Ospedaliero, Brescia, Italy. The authors wish to thank Dott.ssa Miriam Ascagni (Department of Bioscience, Università degli Studi di Milano, Italy) for her skilled assistance in confocal microscopy.

\section{Author Disclosure Statement}

The authors declare that no competing financial interests exist in relation to this article.

\section{References}

1. Dazzi F and NJ Horwood. (2007). Potential of mesenchymal stem cell therapy. Curr Opin Oncol 19:650-655.

2. Hwang NS, C Zhang, YS Hwang and S Varghese. (2009). Mesenchymal stem cell differentiation and roles in regenerative medicine. Wiley Interdiscip Rev Syst Biol Med 1: 97-106

3. Satija NK, VK Singh, YK Verma, P Gupta, S Sharma, F Afrin, M Sharma, P Sharma, RP Tripathi and GU Gurudutta. (2009). Mesenchymal stem cell-based therapy: a new paradigm in regenerative medicine. $\mathrm{J}$ Cell Mol Med 13: 4385-4402.

4. Leung VY, D Chan and KM Cheung. (2006). Regeneration of intervertebral disc by mesenchymal stem cells: potentials, limitations, and future direction. Eur Spine J $15 \mathrm{Suppl}$ 3:S406-S413.

5. Lange-Consiglio A, S Tassan, B Corradetti, A Meucci, R Perego, D Bizzaro and F Cremonesi. (2013). Investigating the potential of equine mesenchymal stem cells derived from amnion and bone marrow in equine tendon diseases treatment in vivo. Cytotherapy 10:1016-1023.
6. Lange-Consiglio A, D Rossi, S Tassan, R Perego, F Cremonesi and O Parolini. (2013). Conditioned medium from horse amniotic membrane-derived multipotent progenitor cells: immunomodulatory activity in vitro and first clinical application in tendon and ligament injuries in vivo. Stem Cell Dev 22:3015-3024.

7. Caplan AI and JE Dennis. (2006). Mesenchymal stem cells as trophic mediators. J Cell Biochem 98:1076-1084.

8. Huang YC, O Parolini and L Deng. (2013). The potential role of microvesicles in mesenchymal stem cell-based therapy. Stem Cells Dev 15:841-844.

9. Ratajczak J, K Miekus, M Kucia, J Zhang, R Reca, P Dvorak and MZ Ratajczak. (2006). Embryonic stem cellsderived microvesicles reprogram hematopoietic progenitors: Evidence for horizontal transfer of mRNA and protein delivery. Leukemia 20:847-856.

10. Camussi G, MC Deregibus, S Bruno, V Cantaluppi and L Biancone. (2010). Exosomes/microvesicles as a mechanism of cell-to-cell communication. Kidney Int 78:838848.

11. Théry C, M Ostrowski and E Segura. (2009). Membrane vesicles as conveyors of immune responses. Nat Rev Immunol 9:581-593.

12. Mathivanan S, H Ji and RJ Simpson. (2010). Exosomes: extracellular organelles important in intercellular communication. J Proteomics 73:1907-1920.

13. György B, TG Szabó, M Pásztói, Z Pál, P Misják, B Aradi, V László, E Pállinger, E Pap, et al. (2011). Membrane vesicles, current state-of-the-art: emerging role of extracellular vesicles. Cell Mol Life Sci 68:2667-2688.

14. Biancone L, S Bruno, MC Deregibus, C Tetta and G Camussi. (2012). Therapeutic potential of mesenchymal stem cell-derived microvesicles. Nephrol Dial Transplant 27: 3037-3042.

15. Bruno S, C Grange, MC Deregibus, RA Calogero, S Saviozzi, F Collino, L Morando, A Busca, M Falda, et al. (2009). Mesenchymal stem cell-derived microvesicles protect against acute tubular injury. J Am Soc Nephrol 20:1053-1067.

16. Zhang HC, XB Liu, S Huang, XY Bi, HX Wang, LX Xie, YQ Wang, XF Cao, J Lv, et al. (2012). Microvescicles derived from human umbilical cord mesenchymal stem cells stimulated by hypoxia promote angiogenesis both in vitro and in vivo. Stem Cells Dev 21:3289-3297.

17. Lange-Consiglio A, B Corradetti, D Bizzaro, M Magatti, L Ressel, S Tassan, O Parolini and F Cremonesi. (2012). Characterization and potential applications of progenitorlike cells isolated from horse amniotic membrane. $\underline{\mathrm{J} \text { Tissue }}$ Eng Regen Med 6:622-635.

18. Schorey JS and S Bhatnagar. (2008). Exosome function: from tumor immunology to pathogen biology. Traffic 9: 871-881.

19. Morel O, F Toti, B Hugel and JM Freyssinet. (2004). Cellular microparticles: A disseminated storage pool of bioactive vascular effectors. Curr Opin Hematol 11:156-164.

20. Deregibus MC, V Cantaluppi, R Calogero, M Lo Iacono, C Tetta, L Biancone, S Bruno, B Bussolati and G Camussi. (2007). Endothelial progenitor cell-derived microvescicles activate an angiogenic program in endothelial cells by a horizontal transfer of mRNA. Blood 110:2440-2448.

21. Cocucci E, G Racchetti, P Podini and J Meldolesi. (2007). Enlargeosome traffic: exocytosis triggered by various signals is followed by endocytosis, membrane shedding or both. Traffic 8:742-757. 
22. Dowling BA, AJ Dart and DR Hodgson. (2000). Superficial digital flexor tendonitis in the horse. Equine Vet J 32: 369-378.

23. Traub-Dargatz JL, MD Salman and JL Voss. (1991). Medical problems of adult horses, as ranked by equine practitioners. J Am Vet Res 198:1745-1747.

24. Prasanna SJ, D Gopalakrishnan, SR Shankar, AB Vasandan. (2010). Pro-inflammatory cytokines, IFN- $\gamma$ and $\mathrm{TNF} \alpha$, influence immune properties of human bone marrow and Wharton jelly mesenchymal stem cells differentially. PLoS One 5:1-16.

25. Sternlicht MD and Z Werb. (2001). How matrix metalloproteinases regulate cell behavior. Ann Rev Cell Dev Biol 17:463-516.

26. Mott JD and Z Werb. (2004). Regulation of matrix biology by matrix metalloproteinases. Curr Opin Cell Biol 16:558-564.

27. Nomura M, Y Hosaka and Y Kasashima. (2007). Active expression of matri metalloptoinase-13 mRNA in Granulation Tissue of Equine Superficial Digital Flexor Tendinitis. J Vet Med Sci 69:637-639.

28. deLaat MA, MT Kyaw-Tanner, AR Nourian, CM McGowan, MN Sillence and CC Pollitt. (2011). The developmental and acute phases of insulin-induced laminitis involve minimal metalloproteinase activity. Vet Immunol Immunopathol 140:275-281.

29. Karousou E, M Ronga, D Vigetti, A Passi and N Maffulli. (2008). Collagens, proteoglycans, MMP-2, MMP-9 and TIMPS in human Achilles tendon rupture. Clin Orthop Relat Res 466:1577-1582.

30. Del Fattore A, R Luciano, L Pascucci, BM Goffredo, E Giorda, M Scapaticci, A Fierabracci and M Muraca. (2015). Immunoregulatory effects of mesenchymal stem cellderived extracellular vesicles on $\mathrm{T}$ lymphocytes. Cell Transplant 24:2615-2627.

31. Magatti M, S De Munari, E Vertua, L Gibelli, G Wengler and O Parolini. (2008). Human amnion mesenchyme harbors cells with allogeneic T-cell suppression and stimulation capabilities. Stem Cells 26:182-192.

32. Engela AU, CC Baan, FJ Dor, W Weimar and MJ Hoogduijn. (2012). On the interactions between mesenchymal stem cells and regulatory $\mathrm{T}$ cells for immunomodulation in transplantation. Front Immunol 3:126.

33. Nauta AJ and WE Fibbe. (2007). Immunomodulatory properties of mesenchymal stromal cells. Blood 110:3499-3506.

34. Galderisi U and A Giordano. (2014). The gap between the physiological and therapeutic roles of mesenchyma stem cells. Med Res Rev 34:1100-1126.

35. Aggarwal S and MF Pittenger (2005). Human mesenchymal stem cells modulate allogeneic immune cell responses. Blood 105:1815-1822.

36. Chabannes D, M Hill, E Merieau, J Rossignol, R Brion, JP Soulillou, I Anegon and MC Cuturi. (2007). A role for heme oxygenase-1 in the immunosuppressive effect of adult rat and human mesenchymal stem cells. Blood 110:3691-3694.

37. Selmani Z, A Naji, I Zidi, B Favier, E Gaiffe, L Obert, C Borg, P Saas, P Tiberghien, et al. (2008). Human leukocyte antigen- G5 secretion by human mesenchymal stem cells is required to suppress $\mathrm{T}$ lymphocyte and natural killer function and to induce CD4 + CD25highFOXP3 + regulatory T cells. Stem Cells 26:212-222.

38. Rossi D, S Pianta, M Magatti, P Sedlmayr and O Parolini. (2012). Characterization of the conditioned medium from amniotic membrane cells: prostaglandins as key effectors of its immunomodulatory activity. PLoS One 7:e46956.

$$
\begin{array}{r}
\text { Address correspondence to: } \\
\text { Prof. Fausto Cremonesi } \\
\text { Large Animal Hospital } \\
\text { Reproduction Unit } \\
\text { Università degli Studi di Milano } \\
\text { Via dell'Università } 6 \\
\text { Lodi } 26900 \\
\text { Italy }
\end{array}
$$

E-mail: fausto.cremonesi@unimi.it

Received for publication November 11, 2015 Accepted after revision February 24, 2016 Prepublished on Liebert Instant Online February 25, 2016 